\title{
Primeras Voces desde el ARCHIVO DE RAFAEL HUMBERTO Moreno-Durán: el “CAPÍtulo CATALÁN"
}

\author{
Voices from Rafael Humberto Moreno- \\ Durán's Archive: "Capítulo CataláN"
}

Juan Carlos Rodríguez Argáez ${ }^{1}$

\begin{abstract}
Artículo derivado de la investigación "El 'Capítulo catalán' y la obra autobiográfica de Rafael Humberto Moreno-Durán”, que fue presentado en 2017 como trabajo de grado para obtener el título de Magíster en Literatura, de la Universidad de los Andes (Colombia). Esta investigación fue dirigida por el profesor Jerónimo Pizarro y hace parte de los resultados del grupo de investigación Archivo y edición.
\end{abstract}

Cómo citar este artículo: Rodríguez Argáez, J. C. (2019). Primeras voces desde el archivo de Rafael Humberto Moreno-Durán: el "Capítulo catalán". Estudios de Literatura Colombiana 45, pp. 85-104. DOI: https://doi. org/10.17533/udea.elc.n45a05

jc.rodriguez557@uniandes.edu.co

Universidad de los Andes, Colombia

Recibido: 22.01 .2019

Aprobado: 10.04.2019

Copyright: $\odot 2019$ Estudios de Literatura Colombiana. Este es un artículo de acceso abierto distribuido bajo los términos de la Licencia Creative Commons Atribución No comercial - Compartir igual 4.0 Internacional

\begin{abstract}
Resumen: este artículo se desarrolla en el marco de la recuperación del archivo del escritor colombiano Rafael Humberto Moreno-Durán. Por un lado, se analiza un texto inédito hallado en su archivo ("Parábola sobre el retorno, trece años después") y se determina que, en algún momento, haría parte del "Capítulo catalán" (1985). Por otro lado, se exponen las razones por las cuales el "Capítulo catalán" se considera la piedra angular de su proyecto autobiográfico (La augusta sílaba), y cómo en este el autor pretende esbozar y constituir un momento de la literatura colombiana y latinoamericana posterior al boom latinoamericano.
\end{abstract}

Palabras clave: R.H. Moreno-Durán; Capítulo catalán; autobiografía; archivo; literatura latinoamericana.

Abstract: This article is developed within the framework of the recovery of the archive of the Colombian writer Rafael Humberto Moreno-Durán. On the one hand, an unpublished text found in his archive is analyzed ("Parábola sobre el retorno, trece años después"), and it is determined that, at some point, it would be part of "Capítulo catalán" (1985). On the other hand, we discuss the reasons why the "Capítulo Catalán" is considered the cornerstone of his autobiographical project (La augusta sílaba), and how in this the author intends to outline and constitute a moment of Colombian and Latin American literature later to the Latin American "boom".

Keywords: R.H. Moreno-Durán; Capítulo catalán; autobiography; archive; Latin American literature. 
Consciente del fin de su estadía en Europa - y dando continuidad al proyecto autobiográfico que había comenzado en 1983 con la publicación de "Fragmentos de La Augusta Sílaba", en 1985 Rafael Humberto MorenoDurán (Ramiriquí, 1945-Bogotá, 2005)1 escribe el “Capítulo catalán”. Si bien la primera idea que puede sugerir el título es que se trata del periodo en que el autor permaneció en Barcelona, vale la pena resaltar que no se limita a este aspecto. De hecho, al leerlo se puede advertir, entre otras cosas, que hablar de Capítulo catalán es evocar un momento de la literatura colombiana y latinoamericana; un periodo aproximado de veinte años en el que un grupo de escritores latinoamericanos, guiados por sus aspiraciones literarias, se radicaron en Barcelona, en donde escribieron y publicaron. Hablar del "Capítulo catalán" no es solamente referirse a un texto autorreferente en el que el autor da testimonio del tiempo que pasó en Barcelona, sino al esfuerzo de un escritor colombiano por cumplir un triple propósito: constituirse como sujeto literario, reclamar el lugar que sentía que le correspondía dentro de la tradición literaria, y escribir el momento de la literatura del cual estaba haciendo parte y que pasaba inadvertido bajo la sombra del boom.

\section{Antecedentes del "Capítulo catalán”}

Si con algún momento de la literatura latinoamericana se llegaron a asociar los nombres de algunos jóvenes escritores que en la década del 70 compartieron la experiencia de escribir fuera de sus países de origen, sería con el boom de la literatura latinoamericana. Esta asociación los obligaba a ser considerados en relación con un grupo con el que no solo no se identificaban, sino contra el que habían luchado vehementemente por apartarse. El apelativo post-boom, con el que se les solía reconocer, invisibilizaba un extenso número de escritores que luchaban por abrirse lugar en medio del hermético espacio que el impacto del boom había creado.

Uno de los ejemplos de esta asociación, que en el caso de la literatura colombiana puede citarse por el extremo carácter de referencialidad temporal que se le otorga a la obra del escritor colombiano perteneciente al boom, es el libro de Juan Gustavo Cobo Borda La narrativa colombiana

La fecha y el lugar de nacimiento de Moreno-Durán es un asunto en el cual no existe un consenso. En la gran mayoría de las reseñas biográficas que se han hecho en sus publicaciones, figura “Tunja, 1946”. El mismo Moreno-Durán solía decir que nació en Tunja en 1946 (así se puede corroborar en algunas cronologías y respuestas a entrevistas que realizó). Sin embargo, este es uno de los asuntos que se logran dilucidar con la posibilidad de acceder a su archivo. Un registro civil nos permite comprobar finalmente que, Rafael Humberto Moreno Durán, nace el 7 de diciembre de 1945 en Santuario, vereda del municipio de Ramiriquí, Boyacá. 
después de García Márquez (1989). En este, el autor, fiel al subtítulo que llevaría el apartado que comparte su nombre con el libro ("Visión a vuelo de pájaro"), hace una somera mención de algunos de esos nuevos escritores, entre los que se encuentran aquellos que, como Moreno-Durán, "llevan ya varios años viviendo en Europa y que logran conciliar una libertad indudable con un trabajo artesanal más riguroso" (Cobo Borda, 1989, p. 114). Además, realiza unas brevísimas reseñas de algunas de las obras de estos autores — seleccionadas con el criterio de haber sido publicadas en 1981- ya que, como supone Cobo Borda, "bien pueden servir para señalar algunas preocupaciones comunes y apuntar hacia determinados virajes" (p. 114). Un análisis de los libros reseñados nos permite ver que más allá del asunto cronológico y del reconocido carácter urbano de su novela El toque de Diana (rasgo que ciertamente compartirá con las demás), Moreno-Durán no se podría considerar como parte de este grupo de jóvenes escritores al que Cobo Borda denomina "la generación del goce pagano", puesto que es la "frivolidad" el criterio que los unifica. ${ }^{2}$ Recordemos que, a manera de conclusión, Cobo Borda termina diciendo: "La literatura colombiana, tan seria y tan tonta, parece haber descubierto, siempre con retardo, en este año de gracia de 1981, las virtudes de la frivolidad" (p. 123).

Por su parte, Ángel Rama parecía haber apreciado con mayor amplitud el asunto de las generaciones posteriores al boom. Había advertido tanto las ventajas del auge editorial que este representó para el resto de los escritores latinoamericanos, así como la enorme dificultad que significó - para los contemporáneos y posteriores- hacerse a un lugar en el campo de la literatura latinoamericana. Ya en el título del prólogo de su antología Novísimos narradores hispanoamericanos en marcha (1982) — "Los contestatarios del poder"-, Ángel Rama daría cuenta de ello. Con esta alusión de indiscutible tinte político, señala la emergencia de un conjunto de escritores cuyos intereses y pretensiones estéticas tuvieron que enfrentarse fervorosamente a los establecidos por el boom. Al respecto, Rama (1982) dirá que

Desde 1964 los lectores vivieron el regocijo de una suerte de inagotable cuerno de la fortuna, ya que junto a las nuevas obras de los grandes narradores disfrutaban como nuevas de las reediciones de toda su producción anterior. Hubo una jubilosa

$\overline{2} \quad$ Los libros reseñados son: El toque de Diana, de R.H. Moreno-Durán; La mala hierba, de Juan Gossaín; Celia Cruz: Reina Rumba, de Umberto Valverde; Fiesta en Teusaquillo, de Helena Araújo; Gentecita del montón, de Roberto Rubiano Vargas, y El último macho y otros cuentos, de Antonio Morales Rivera. 
borrachera inicial, la candorosa certidumbre de que la excelsitud artística era el pan nuestro de cada día, de que lo mejor por lo que bregábamos era también lo que la sociedad reclamaba. Después comenzamos a percibir las distorsiones y resquebrajaduras de ese cuadro idílico [...] cuando pareció que el sedicente boom iba camino de constituirse en una restringidísima fortaleza que pretendía detener el tiempo, contener lo que es más importante que todo: la fuerza creadora de la pujante sociedad latinoamericana (pp. 458-459).

Quizás porque Ángel Rama advierte con claridad la supremacía del boom, preferirá denominar a esta "generación de veinteañeros a los que habría de esperar una ruda pelea para encontrar su voz propia entre los innumerables ecos que repetían el modelo triunfante de los mayores" (p. 459) con el apelativo de "Novísimos escritores latinoamericanos". Bien visto, con este gesto realiza un quiebre nominal que, si bien puede parecer insignificante, les concede una independencia sin precedentes.

Si bien es cierto que en términos generales el propósito de esta nueva generación pudo haber sido oponerse a los principios estéticos del boom, ${ }^{3}$ es posible que el ejemplo más contundente de esta enérgica lucha, en la literatura colombiana, sea la novela El titiritero (1977), del escritor colombiano Gustavo Álvarez Gardeazábal. Tal como lo menciona el crítico estadunidense Seymour Menton, en un apartado de su libro La novela colombiana: planetas y satélites (1978), en esta novela de Gardeazábal, la influencia de la obra de García Márquez es rehusada abierta y drásticamente. En ella, el narrador le aclarará al lector que

No va a encontrar ningún divertimento árabe ni ninguna caja china de esas que los novelistas usan para atraer al lector. Estará usted siempre con los pies en la tierra, no se montará en ninguna alfombra voladora ni le van a llover mariposas amarillas desde el cielo (Gardeazábal, citado. en Menton, 1978, p. 359).

Tanto Menton como Rama identifican en la nueva literatura colombiana el propósito de escapar al Realismo Mágico. Ángel Rama reconocerá este gesto en la recuperación del realismo, mientras que Menton (1978) lo hará por medio de lo que consideró un proceso de desmitificación, ya que, según él, "Desde Asturias y Carpentier hasta García Márquez y Carlos Fuentes, la novela se ha caracterizado por la mistificación de la realidad" (p. 360). Recuperación del realismo o desmitificación, lo cierto es que el

De los cuales quizás los más destacados serían Reinaldo Arenas, Severo Sarduy, Ricardo Piglia, Manuel Puig, Luisa Valenzuela, Luis Fayad, Salvador Elizondo, Óscar Collazos, Umberto Valverde y el propio Moreno-Durán, entre otros. 
momento histórico en el cual se desarrolla (y ante el cual responde) el trabajo literario de estos "novísimos escritores latinoamericanos" -incluido el de Moreno-Durán- estuvo drásticamente marcado por aquel fenómeno literario y editorial que recibió el nombre de boom. Dicho de otra manera, por la implacable influencia de consumados escritores como Julio Cortázar, Carlos Fuentes, Mario Vargas Llosa, Gabriel García Márquez, Jorge Edwards y José Donoso, entre otros.

\section{"Parábola sobre el retorno, trece años después" (el fragmento suprimido): los motivos del "Capítulo catalán” más allá del garciamarquismo}

Por su carácter dialógico - por las evidentes alusiones que hará en contra de la fuerte influencia que la obra de Gabriel García Márquez ejercería en la literatura colombiana-, los motivos del "Capítulo catalán" se pueden rastrear en el espíritu contestatario de estos "novísimos escritores latinoamericanos". No obstante, un texto mecanografiado, hallado en el archivo de MorenoDurán, intitulado "Parábola sobre el retorno, trece años después", nos permite descubrir una razón que le brinda un sentido más completo a los que podrían ser sus motivos (Moreno-Durán en Rodríguez, 2017. Anexo virI). ${ }^{4}$

Además del contenido, unas anotaciones al margen nos brindan indicios de que este texto habría hecho parte del "Capítulo catalán”. En la tercera página se encuentra una anotación a mano que dice: "Todo esto se religó. Sigue en la Pag.13", con la cual adquiere sentido la anotación — "Pag.13"- que se encuentra en la primera página de "Parábola sobre el retorno". En este documento existen algunos fragmentos que fueron escritos a mano y después dactilografiados, unos reubicados, otros suprimidos. Por ejemplo, en las páginas $6,8,16$, y 17 se pueden apreciar vestigios de estos cambios. Ahora, el fragmento que Moreno-Durán selecciona en "Parábola sobre el retorno", el cual indica que "continúa en la página 13" (de un texto desconocido), coincide en contenido y ubicación con la tercera versión del "Capítulo catalán" encontrada en el archivo (Moreno-Durán en Rodríguez, 2017. Anexo viII, p. 120 y Anexo IX, p. 156).

La importancia de este hallazgo, en el propósito de develar los posibles "motivos del Capítulo catalán", quizás no se encuentre tanto en lo

$4 \quad$ Como los textos "Parábola sobre el retorno, trece años después" y "Capítulo catalán" mencionados en este artículo se tratan de ediciones dactilografiadas encontradas en el archivo de R.H. Moreno-Durán, las referencias bibliográficas que se harán remiten a la tesis que consigna en sus anexos dichos textos: Rodríguez, Juan C. (2017). "El ‘Capítulo catalán' y la obra autobiográfica de Rafael Humberto Moreno-Durán”. Universidad de los Andes, Bogotá. 
que se ha conservado de este como en lo que Moreno-Durán decidió omitir. El descubrimiento de la correspondencia entre "Parábola del retorno, trece años después" y el "Capítulo catalán", nos permite advertir que, además de la consabida animosidad contra el imperante garciamarquismo, este "capítulo" habría sido - por lo menos en algún punto- la respuesta de Moreno-Durán ante el desconocimiento que de su obra se hace en el libro La novela colombiana: planetas y satélites (1978), de Seymour Menton. Esto no se logra advertir en la versión publicada del "Capítulo catalán", puesto que todas las alusiones a este libro o a su autor fueron suprimidas. Sin embargo, en la tercera versión, recuperada del archivo, se puede ver que aparentemente, en la segunda revisión que Moreno-Durán le hace al texto, termina de tachar el resto de estas alusiones (Moreno-Durán en Rodríguez, 2017. Anexo IX, p. 160).

Para comprender mejor este asunto hace falta hablar un poco de este libro. El símil que Menton sugiere desde el título es bastante claro; con planetas hará referencia a ciertas obras de considerable importancia alrededor de las cuales orbitarán —como satélites - aquellas menos importantes, que "sin embargo - dirá Menton- merecen leerse y estudiarse por sus propios valores intrínsecos y por la posibilidad que ofrecen de descubrir las imperfecciones o debilidades que les han impedido alcanzar la misma categoría de las cuatro grandes" (Menton, 1978, p. 6). Para Menton, estas cuatro novelas fundamentales de la historia de la literatura colombiana serán: María (1867), de Jorge Isaac, Frutos de mi tierra (1896), de Tomás Carrasquilla, La vorágine (1924), de José Eustasio Rivera, y Cien años de soledad (1967), de Gabriel García Márquez. Cada una de estas novelas será la obra cumbre de su respectivo momento en la literatura colombiana: el romanticismo, el realismo, el criollismo, y el boom (Menton, 1978, p. 5).

Si bien el análisis que se plantea en este libro llega hasta el auge de la literatura latinoamericana, conocido como boom, es posible que MorenoDurán se haya sentido ignorado debido a que, en el prólogo, Menton (1978) dirá haber conocido en Bogotá, Cali y Medellín a un gran número de autores, críticos y aficionados a la literatura con quienes pudo conversar acerca de su libro, así como de otras obras que merecían ser consideradas (p. 11). Entre las personas a quienes Menton pide disculpas - "por no haber dedicado un capítulo a la obra predilecta de alguno de ellos" (pp. 11-12) - se encontrarán nombres de autores menores y contemporáneos de MorenoDurán, sin que él haya sido tenido en cuenta. Este sería el caso de Fanny 
Buitrago e Isaías Peña Gutiérrez, ambos nacidos en 1943, o de Gustavo Álvarez Gardeazábal, nacido en 1945, entre otros.

La relación entre el libro de Menton y "Parábola sobre el retorno, trece años después" es incuestionable. Los indicios de esta relación se plantean desde el título. En todo caso, debemos tener en cuenta que este posee un carácter polisémico cuyos significados más amplios solo se logran aprehender cuando se ha leído el texto. Observemos que, en una primera aproximación, el vocablo "parábola" nos hará pensar que se refiere a una narración de la que se deduce, por comparación o semejanza, una enseñanza. Sin embargo, un análisis del título, posterior a la lectura del texto, nos permitirá conjeturar dos posibles interpretaciones más. Por una parte, con "parábola" aludirá a la figura que crean los cuerpos celestes del sistema solar, conforme a la forma elíptica en que orbitan. Acepción que, como veremos más adelante, ocupará un lugar fundamental. Por otra parte, esta forma elíptica se podría relacionar con cierto tipo de tratamiento del lenguaje presente en el texto. Es decir, podemos entender "parábola" como la trasnominación de elipsis; figura retórica — de la que se sirve MorenoDurán- que consiste en la omisión de algunos elementos del discurso que darán como resultado la inevitable reciprocidad del lector.

Ahora, el título no alude exclusivamente a uno de estos posibles significados. Su virtud radica justamente en la ambivalencia. Podemos decir entonces que se tratará de un texto del que se deduce una verdad, en el que se utiliza el movimiento elíptico de un cuerpo celeste como metáfora, y en el que a través de la omisión - o del soslayo - se darán a conocer sus propósitos. El primer ejemplo que se puede encontrar de estos tres sentidos que se le ha dado a "parábola" corresponderá con el de la omisión como figura retórica; como recurso literario. Bastará leer el comienzo para reconocerlo:

Hace algunos años, un destacado estudioso de nuestra literatura se enfrentó a la labor de clasificar a los productores según su valor e influencia y, en vista de la ardua delimitación que le imponía el trabajo, optó por dividir a sus fieles en dos grandes bloques de inequívoca resonancia astronómica, tal vez porque astronómica era la diferencia entre la obra de unos, a los que llamó planetas, y otros, a los que llamó satélites (Moreno-Durán, en Rodríguez, 2017. Anexo viII, p. 120).

Si bien Moreno-Durán no menciona a Seymour Menton ni el título de su libro, la alusión es tan evidente que no necesita hacerlo. Este mismo 
efecto se logrará cuando insinúa el predominante lugar que ocupa la figura de García Márquez en la literatura colombiana:

Muchos autores se creyeron así cerca de los cielos, o sea de la gloria, aunque según el análisis resultaran meras lunas de Júpiter o Saturno, y otros asumieron su papel de planetas, aunque en el caso de nuestro sistema todavía no queda claro — aunque lo sospecho- a quien le corresponde el papel de Sol (p. 120).

Existe también un fragmento en el que se corroboran los otros dos sentidos que se le han dado a la palabra "parábola":

Siempre en sentido opuesto al sol, el cometa traza una elipse de gran excentricidad y su apéndice es largo y luminiscente como modestamente espero sea algún día el influjo de mi escritura. Pero más allá de las esplendidas geometrías de su trayecto, el cometa se funda con mi voluntad filológica, pues aunque sus órbitas suelen ser elípticas, a veces, a causa de su excentricidad, alcanza la unidad - como era el propósito de la trilogía Femina Suite- y su órbita deviene parábola, como ésta que ahora les cuento sobre los astros, aunque parábola también lo era mi discurso sobre lo femenino [...] Pero, aparte de esas órbitas clásicas, el desplazamiento del cometa puede ser una hipérbole, a falta de una hipérbola (p. 122).

En estos fragmentos podemos observar que el sentido polisémico del título se despliega y que estas acepciones responden al símil que Menton propone. De esta manera, aquel sentido de "parábola", que describe el trasegar de un cuerpo celeste, cobra pleno sentido. De hecho, se puede advertir que, en el marco de esta semejanza, Moreno-Durán se reconocerá como Cometa. Una coincidencia le servirá para incluirse de este modo en la analogía. Justo en 1986, año en el que vuelve a Colombia después de trece años de residir en Barcelona, se da un acontecimiento astronómico que se repite, aproximadamente, cada 76 años: el paso del cometa Halley. Suceso del cual, R.H. dirá que "cualquier aficionado a la adición mágica se dará cuenta de la reconfortante casualidad, pues basta descomponer los elementos del guarismo 76, sumarlos y obtener como resultado el número 13, que no sólo es mi número de suerte sino también el lapso que he permanecido ausente de mi país" (p. 122).

Dada la convergencia de estos dos acontecimientos excepcionales, Moreno-Durán entablará una relación que usará para incorporarse en el universo descrito por Menton. Su ingenio consistirá en realizar una 
ampliación del símil. Es decir, en crear una categoría que, si bien no existe, le corresponde a cabalidad. Con esta argucia no solo reclama un lugar en la tradición literaria, también manifiesta su tenaz propósito de distanciarse de cualquier clasificación de su obra en el marco de lo que era la literatura colombiana, en especial del influjo de la obra de García Márquez. Tanto la alusión directa a Menton como su lugar en el símil que este propone se aprecian en el siguiente fragmento:

[...] no me sorprendí cuando se me planteó la posibilidad de visitar mi país, invitado precisamente por razones inherentes a mi obra literaria, y eso que yo no era ni planeta ni satélite. Miré una vez más el cielo y descubrí no ya un eclipse sino la estela luminosa del cometa Halley. Y fue entonces cuando tuve la certeza de que mi destino estaba desde siempre escrito Allá Arriba [...] y que acababa de descubrir mi verdadera identidad (Moreno-Durán en Rodríguez, 2017. Anexo viII, p. 122).

En este fragmento se toca tangencialmente lo que en esencia no solo será el motivo de "Parábola sobre el retorno" o del "Capítulo catalán”, sino el de la totalidad de La Augusta Sílaba: la incesante inquietud de MorenoDurán en relación con su identidad y su existencia como narrador; el afán de reclamar su lugar en una tradición literaria que, según lo manifiesta en este texto, fue apática a su obra. Así lo dirá Moreno-Durán:

Obviamente no era yo un planeta, puesto que mi juventud y mi campo gravitatorio no me hacen responsable de ninguna escuela, moda o movimiento, al menos por ahora; tampoco era un satélite, puesto que la propia crítica de mi país se empeñó desde el comienzo en señalar mi soberbia, mi fastidiosa independencia, mi imperdonable alejamiento de las magnas órbitas que definían la prestigiosa literatura colombiana (p. 120).

Planeta, Satélite o Cometa, en todo caso, el motivo que subyace en el proyecto autobiográfico de Rafael Humberto Moreno-Durán - y que quizás en ninguna otra parte lo manifiesta más claramente que en "Parábola sobre el retorno" (texto del que un poco menos de la mitad se conservaría en la versión mecanografiada, y que se suprime completamente en la versión publicada del "Capítulo catalán”) — será su afán de encontrar un lugar en la literatura nacional. A esto hará referencia cuando asegura que "Como lo único que quedaba claro es que yo pertenecía a esta galaxia, tenía que buscarme un lugarcito propio, no fuera que algún científico desvelado me descubriera una noche y me confundiera con un ovni o un asteroide" (p. 120). 
Responder a esta necesidad identitaria, sin que esto signifique tener que adherirse a algún grupo o movimiento, prevalece sobre cualquier otra posible intención de Moreno-Durán. De hecho, se puede decir que aún su recalcitrante actitud contra la emblemática figura de García Márquez surgiría de esta angustia ontológica. Pensemos, por ejemplo, cuando se pregunta "¿quién era yo para permanecer inmune al virus de la maconditis, para vapulear a nuestra queridísima literatura de la violencia, para ignorar a nuestros gamines y chinos de la calle?" (Moreno-Durán en Rodríguez, 2017. Anexo VIII, p. 122). El hecho de que generalmente incluya otros ejemplos de la literatura colombiana nos demuestra que no se trata de un asunto que tenga que ver específicamente con la obra de García Márquez. Sí, acaso, con la descomunal sombra que su figura desplegaría sobre sus coetáneos y sucesores.

Por otra parte, en "Parábola sobre el retorno" se encuentra tan marcada la apropiación del símil de Menton que, de no haberlo suprimido, el verdadero propósito del "Capítulo catalán" habría sido desplazado. Démonos cuenta de que incluso esta inquietud tan significativa para Moreno-Durán se manifiesta dentro de la misma lógica: "con la vista puesta en el diorama celeste [...] una noche de ontológico insomnio me tomé la libertad de preguntarme cuál era el lugar que mi modesta obra ocupaba en el concierto de las constelaciones patrias" (p. 120). Las referencias son tan evidentes que de no haberlas suprimido del "Capítulo catalán” parecería que lo esencial fuera responder a Menton.

\section{Entre Quijote y Juan Preciado: estrategias textuales en el “Capítulo catalán"}

Con relación a su propósito de inscribirse en la tradición literaria, podemos ver que aun cuando en Como el halcón peregrino R.H. dice que su intención era registrar la "fiel sucesión de afectos y lealtades" que mantuvo con algunos escritores, ya que estas le permitieron comprobar que él también era memoria (Moreno-Durán, 1995, p. 11) —es decir, que también hacía parte de la historia de la literatura latinoamericana-, en ningún otro texto de los que comprenden La Augusta Sílaba se plasma, tan rotundamente, su afán por hacer parte de la tradición literaria como en el “Capítulo catalán". Por esta razón, dicho texto se puede considerar el eje del vasto conjunto de su producción autobiográfica.

Cualquiera que conozca su trayectoria como escritor podrá argüir que los cerca de quince años que reside en Barcelona ocupan un periodo 
insoslayable de su vida, y que el asunto no requeriría mayor atención. No obstante, la relevancia de este Capítulo trasciende dicha obviedad. De hecho, si el halcón peregrino es la tentativa de legitimar su "alto vuelo" a través del trato que mantuvo con algunos de los más significativos representantes de la literatura latinoamericana, ${ }^{5}$ esta intención podría entenderse como la ampliación del sentimiento que habría comenzado a materializarse años atrás en el "Capítulo catalán".

Así las cosas, este "capítulo" —entendido también como el periodo de su vida que va desde 1973 hasta 1988 - resulta imprescindible para el estudio y la comprensión de su proyecto autobiográfico. El "Capítulo catalán”, más allá de ser un particular recuerdo barcelonés - como a primera vista nos podría hacer creer su nombre-, representa la intención de escribir un momento en la historia de la literatura colombiana y latinoamericana con el cual no solo por fin se identifica Moreno-Durán, sino en el que él mismo es su principal integrante. En este sentido, el texto es testimonio de la urgencia de un escritor colombiano por inscribirse, más que en la literatura nacional, en un momento de la historia latinoamericana y universal.

Analicémoslo desde el comienzo. En el primer párrafo del "Capítulo catalán" se logran advertir dos alusiones literarias que, vistas a la ligera — como resultado de una simple pretensión lúdico-creativa-, podrían llegar a entenderse y tildarse de artificiosas y poco significativas. Sin embargo, lejos de serlo, son una excelente muestra de la pericia con que Moreno-Durán, sirviéndose de su acervo literario, postula los puntos centrales sobre los que ahondará. En aras de una mejor comprensión, hace falta citar dicho comienzo:

Vine a Barcelona porque me dijeron que aquí había vivido mi antepasado, don Antonio Moreno, célebre por haberle dado hospitalidad a Don Quijote durante su estancia en la ciudad. Supe entonces que mi destino estaba de alguna forma asociado al suyo, aunque más allá de los nominativos lo que en realidad me unió definitivamente a Barcelona fue el pasaje en que Don Quijote, al pasear por las cercanías de la casa donde se alojaba — probablemente en la calle Montcada-, descubrió un letrero que decía "Aquí se imprimen libros" (Moreno-Durán, 1986, p. 114).

Así lo dirá en Como el halcón peregrino: "De las treinta y tres semblanzas que conforman este volumen [...] más de veinte han sido motivadas por un trato directo con los autores -en mayor grado de amistad en unos que en otros-, trato casi siempre surgido e incrementado por la experiencia común de congresos, viajes e incluso razones de vecindad a lo largo de muchos años" (Moreno-Durán, 1995, p. 10). 
Es evidente que estas alusiones pasan inadvertidas si se desconoce el emblemático inicio de Pedro Páramo, la "existencia" de aquel "caballero rico y discreto y amigo de holgarse a lo honesto y afable": Don Antonio Moreno (Don Quijote II, LXII, p. 1021) y, por extensión, aquella experiencia de Don Quijote en la imprenta.

Puesto que en estas alusiones de aparente intrascendencia se podrían entrever algunas manifestaciones de su subjetividad, ${ }^{6}$ sería conveniente analizarlas individualmente. Con la recreación del inicio de Pedro Páramo, R.H. lograría metafóricamente dos cosas. En principio, presentarse como un sujeto literario; como un protagonista de la literatura latinoamericana. El hecho de que Juan Preciado vaya a Comala en busca de su padre correspondería con la intención de R.H. de ir a Barcelona en busca de los antepasados de su vocación literaria. Claramente, es su apellido paterno lo que le sirve de "acorde pivote" para entablar la relación ficcional que le permite moverse entre Pedro Páramo y el Quijote; entre Juan Preciado y el Caballero de la triste figura; entre Bogotá y Barcelona. Asimismo, R.H. manifestaría el sentimiento de haber llegado a Barcelona sin lo que consideraba una "prehistoria literaria", sirviéndose de la imagen de aquella realidad fantasmagórica con la que se encuentra Juan Preciado al llegar a Comala. Al respecto, vale la pena recordar que este sentimiento de "desolación" ante la falta de un pasado literario se puede advertir con claridad en una entrevista que le hace Gabriel Restrepo en el 2004. Observemos que ante el comentario que le hace Restrepo con relación al hecho de que, al irse a Barcelona, R.H. llevara el manuscrito de sus primeras obras (De la barbarie a la imaginación y Juego de damas), Moreno-Durán responderá:

No, es que yo no llevaba nada, eso es como si nada; y recuerdo que cuando yo llego a Barcelona, todos los latinoamericanos que estaban allí tenían cuatro o cinco libros publicados, es decir, entre la gente de mi generación: Collazos tenía cuatro libros y todos los demás tenían cinco, diez, para no hablar de monstruos como Vargas Llosa, García Márquez o José Donoso que eran así los absolutamente consagrados. Entonces yo ¿a qué iba? Es decir, yo no había perdido mi virginidad editorial (Restrepo, 2014, p. 18).

Con relación al pasaje de Quijote en la imprenta, se pueden advertir varias cosas. En principio, que la importancia de Barcelona en el campo

$6 \quad$ Así lo sugiere R.H. cuando refiriéndose a su parodia del inicio de Pedro Páramo, dice: "a mí me pareció que era una broma mía y sin embargo pienso a medida que pasan los años que yo nunca estuve más certero que en esa frase" (Restrepo, 2014, p. 14). 
editorial es lo que lleva a Moreno-Durán a establecerse en esta ciudad y no en otra. Esta asociación que establece Moreno-Durán (1986) entre la escena de Quijote en la imprenta y la importancia de Barcelona se corrobora cuando dice que "basta recordar que no en vano Barcelona es la capital mundial de la edición en lengua castellana y que de tal hecho dio testimonio don Quijote en su visita a la imprenta" (p. 122). En suma, la alusión de esta escena le sirve a Moreno-Durán tanto para resaltar el ambiente propicio que reconoce en Barcelona para sus aspiraciones editoriales como para reafirmarse como sujeto literario. Además de esto, en la descripción de dicho pasaje podemos advertir el altísimo criterio que le atribuía a cualquier oficio que tuviera que ver con lo literario. Lo cual, bien visto, no es otra cosa que una apreciación indirecta de sí. Veámoslo:

Aparte de los elogiosísimos comentarios que Don Quijote hace de Barcelona, el mayor homenaje a la ciudad condal está dado en este fragmento donde la urbe se funde con la magna actividad de la edición de libros. En ese ambiente viví durante trece años y muchas veces, también yo, me sentí don Antonio Moreno, dispuesto a dar albergue a toda clase de entes de ficción, que es tanto como decir, seres de lenguaje (p. 115).

Ahora bien, este pasaje adquiere otros sentidos. Por una parte, se puede asociar con la intención de Moreno-Durán de dar a conocer su experiencia en el desempeño de distintas labores en la industria editorial. Esta posible acepción la confirmará cuando dice:

Yo mismo, a lo largo de estos trece años, he sido en orden riguroso lector, traductor, Director literario y Asesor de Proyectos Editoriales. Y si los primeros trabajos me enseñaron algunos de los secretos del oficio, los dos últimos me sumieron peligrosamente en la burocracia de la edición. La experiencia, pues, ha sido casi completa, y como ocurrió con el ilustre ejemplo tantas veces citado, también yo he sido operario, personaje y autor de mis propios libros (p. 121).

Por otra parte, también se puede relacionar con el deseo de descubrirse, del mismo modo que don Quijote, protagonista de una historia, que en este caso no es otra que la de la literatura latinoamericana. Entendido de esta manera, la importancia que Moreno-Durán le otorga a esta icónica escena metaficcional, en la que el héroe cervantino - personaje literario por antonomasia- ingresa a la imprenta en donde se está trabajando en un libro que trata de sí, daría cuenta de este deseo. 
En el marco de esta similitud, el "Capítulo catalán" será la historia de un escritor que crea la historia en la que él mismo será el personaje; será aquel pasaje de la literatura latinoamericana en el que -como don Quijote- Moreno-Durán se reconoce protagonista. Con la diferencia de que en esta oportunidad habría tenido que ser el mismo personaje quien la escribiera. La relación de este fragmento con la pretensión autobiográfica de constituirse como sujeto literario, y protagonista de un momento de la literatura latinoamericana, se ratifica al final del texto, cuando MorenoDurán (1986) dice que

Cuando buscaba las huellas de mi antepasado, don Antonio Moreno, descubrí también el letrero que anunciaba la edición de libros, entré en la casa y, trece años después, aún no he podido salir de ella, fascinado y atareado en la redacción, corrección e impresión de este Capítulo cuyo apretado resumen no es más que una página furtiva pero entrañable de mi memoria (p. 122).

En suma, más que una simple tentativa emancipadora o un gesto renuente frente a la literatura nacional y al realismo mágico, el "Capítulo catalán” es la manera en que Moreno-Durán nos deja saber el momento de la literatura al que perteneció.

\section{El Capítulo catalán (1965-1987): un momento de la literatura colombiana y latinoamericana}

Hasta el momento, con "Capítulo catalán” se ha aludido al texto homónimo que se publica por primera vez en 1985. En otras palabras, nos hemos limitado a considerar uno de los fragmentos que conforman el conjunto de su experiencia vivida; proyecto autobiográfico al que, con la intención de señalar su calidad de obra en continuo desarrollo, tituló La Augusta Sílaba. Sin embargo, hablar de Capítulo catalán es evocar un momento de la literatura, un periodo aproximado de veinte años en el que un grupo de escritores latinoamericanos, siguiendo sus aspiraciones literarias, se habría ido a vivir a Barcelona. Si lo acotamos al ámbito de la historia de la literatura nacional, es hablar de uno de los diferentes capítulos que tratarían de la literatura de la diáspora. En este caso particular - como su nombre lo indica-, de aquella que se habría establecido en Barcelona. Siendo así, considerar la figura de Moreno-Durán dentro de dicho momento de la literatura es atender a un caso específico de este periodo. También es pensar en un escritor que advierte y escribe el momento histórico del cual 
hace parte. En este otro sentido, el "Capítulo catalán” es el testimonio de este periodo, y R.H., amanuense y personaje.

Esta especie de caja china, esta historia dentro de otra, que se despliega cuando se considera el "Capítulo catalán" como momento histórico y, a la vez, como texto que da cuenta de él -o a Moreno-Durán como historiador y personaje de su momento- se logra apreciar cuando R.H. esclarece el sentido del texto:

Hablo de Capítulo catalán para diferenciarlo de otros eventuales capítulos de nuestra literatura en la diáspora, como serían un Capítulo mexicano, bonaerense o parisino o madrileño, cuyas páginas registrarían los avatares de los escritores colombianos - y, por extensión, latinoamericanos - en esos lugares, así como su respectiva experiencia bibliográfica. En este sentido, queda claro que mi Capítulo personal representaría apenas unos párrafos del Capítulo catalán, que a su vez ocupa una breve página del Capítulo de nuestra narrativa escrita fuera de sus fronteras, que a su vez remite a un más amplio Capítulo de la literatura colombiana contemporánea, y no quieran los dioses que a su vez todo esto constituya un Capítulo de la historia universal de la infamia (Moreno-Durán, 1986, p. 119).

Ahora bien, si se conviene en que el "Capítulo catalán” es la tentativa de escribir un momento de la literatura colombiana y latinoamericana, uno se podría preguntar por qué Moreno-Durán no lo hace en el marco de su obra ensayística. Pensemos que si el capítulo se tuviera que incluir en alguno de sus libros, y el principio histórico fuera el principal criterio para hacerlo, este libro no podría ser otro que Denominación de origen: momentos de la literatura colombiana (1998). Como el subtítulo lo expresa, en este libro R.H. elabora un recuento de los momentos de la literatura nacional. Este análisis irá desde "La escritura de las fundaciones" hasta el periodo que corresponde a una generación anterior a la suya, es decir, al boom. En otras palabras, si se llevara a cabo una actualización de este libro atendiendo al orden cronológico sobre el que está construido, nos daríamos cuenta de que ningún otro momento le sucedería más claramente que el de aquella "Generación Trashumante" a la que Luz Mary Giraldo llamaría la "generación de la ruptura"7 o "del deslinde del boom". Por supuesto,

\footnotetext{
$\overline{7} \quad$ Esta definición se puede encontrar en el prólogo del libro Cuentos caníbales: Antología de nuevos narradores colombianos, titulado: "Después de las grandes rabias y los hermosos errores" (Giraldo, 2002, p. 11).

8 Esta definición se puede encontrar en una ponencia titulada "R.H. Moreno-Durán: contemporáneo del porvenir", presentada en el marco del xxviI Congreso Nacional y I Internacional de Lingüística, Literatura y Semiótica. Universidad Pedagógica y Tecnológica de Colombia - Sede Tunja, del 9 al 12 de octubre de 2012.
} 
pertenecería a este periodo aquel conjunto de escritores latinoamericanos que residieron en Barcelona bajo la sombra de esa suerte ambivalente que fue el boom de la literatura latinoamericana, a la que Moreno-Durán enmarca en un lapso bajo el nombre de "Capítulo catalán". Volviendo a la cuestión de por qué no incluye este en su obra ensayística y, por el contrario, lo incluye dentro de su obra autobiográfica, en el liminar de Denominación de origen podemos hallar una respuesta:

Juez y parte en el asunto, el autor se abstiene de hacer consideraciones sobre el tiempo nublado que le ha correspondido vivir y es otra mirada crítica la que debe ocuparse de dilucidar las carencias o aportes con que la Generación Trashumante ha empobrecido o enriquecido la tradición literaria del país (Moreno-Durán, 1998, p. 10).

Cuando R.H. dice ser "juez y parte" enuncia los dos tipos de aproximaciones que podría llegar a realizar. Estos corresponden, respectivamente, al ensayo y la autobiografía. Con "juez” se podría pensar en la aparentemente distante e imparcial aproximación que sugiere la escritura ensayística. Con aquello de ser "parte", indudablemente, en la aproximación más subjetiva de quien ha sido partícipe de la historia que narra, es decir, con la escritura autobiográfica. Si bien ser al mismo tiempo "juez y parte" pudiera ubicarlo en un punto medio entre la ensayística y la autobiografía, parece que la falta de objetividad que Moreno-Durán encuentra en el hecho de que sea él mismo quien señale el momento de la literatura al que pertenece, lo lleva a ubicar este texto en un ámbito en el que la subjetividad se encuentra un poco más a sus anchas. Quizás sea en este punto en donde mejor se logre ver la estrecha relación que existe entre el ensayo y la autobiografía, así como las posibles razones que llevan a un autor a tratar determinados asuntos utilizando uno de estos dos tipos de escritura.

El "Capítulo catalán" transita estilísticamente entre el ensayo y la autobiografía; entre lo contundente que sugiere la imagen del "juez" y el testimonio tendencioso pero irremplazable de quien ha hecho "parte" de lo que relata. Por supuesto, Moreno-Durán sabe que para consolidar un momento de la literatura debe considerar y definir cuestiones formales como su denominación, cómo se enmarca y se divide históricamente, quiénes lo integran, qué obras hicieron parte de este momento, etc. $\mathrm{Su}$ propósito se hará evidente desde el segundo párrafo de la segunda página 
del “Capítulo catalán”. En este, R.H. se pregunta “¿cómo ignorar aquí esa larga lista de escritores que en los últimos veinte años han hecho de Barcelona su refugio y su lugar de trabajo?". Bien visto, en esta pregunta retórica involucra tres de los mencionados aspectos. Primero, el asunto de los integrantes; segundo, el tiempo que duraría, y tercero, el porqué de su nombre. Sobre este último aspecto dirá que se llama Capítulo catalán "porque la común experiencia catalana forma ya parte de la biografía de todos aquellos que - supongo- por exigencias y expectativas del oficio hemos vivido largos años en Barcelona" (Moreno-Durán, 1986, p. 115). Por otra parte, su respuesta esclarece los criterios que le darán unidad a dicho momento. Para empezar, se tratará de la "común experiencia" que habrían compartido algunos escritores latinoamericanos al residir y escribir en Barcelona, teniendo en cuenta que sus integrantes se caracterizarán por haber emigrado a esta ciudad respondiendo a sus aspiraciones literarias. Quizás por esta razón, justo después de esta respuesta, agregará que "Las razones por las que algunos colombianos recalamos en esta ciudad son tan diversas y a diferencia de escritores de otros países de América Latina en ningún caso obedecieron al patético imperativo del exilio forzoso que por la misma época desmanteló el mapa cultural y político del continente” (p. 115).

Respecto al tiempo, hará falta precisar el lapso de veinte años que Moreno-Durán menciona. Si bien R.H. identifica a José María Vargas Vila, a Antonio José Restrepo, y a Jorge Zalamea como antecesores de "una larga y ya tradicional peregrinación de escritores a Barcelona" (p. 115), será solo con la llegada de la escritora colombiana Alba Lucía Ángel a esa ciudad, en 1965, que R.H. reconoce el inicio de un primer momento del Capítulo catalán. A este periodo lo denomina el de "el grupo de los ilustres" debido a "la presencia triunfal" de Gabriel García Márquez, Mario Vargas Llosa, José Donoso y Jorge Edwards, integrantes del boom que residían en Barcelona. Este primer periodo, de acuerdo con el "Capítulo catalán”, terminará en 1979, año en el que los últimos dos "ilustres", Jorge Edwards y José Donoso, dejarían la ciudad. ${ }^{9}$

En términos generales, el Capítulo catalán como periodo histórico consta de dos momentos. El primero (de 1965 a 1972 aproximadamente) marcado por la presencia del grupo de "los ilustres". El segundo (de 1972

$9 \quad$ Estas fechas corresponden con lo que se menciona en el "Capítulo catalán": "la desbandada del grupo de los ilustres la inició Vargas Llosa en 1974, la continuó García Márquez el año siguiente, y la culminaron Donoso y Edwards en 1979" (Moreno-Durán, 1986, p. 115). Sin embargo, estas fechas se tendrían que reconsiderar puesto que es bastante conocido que Jorge Edwards regresa a Chile en 1978 y José Donoso en 1981. 
a 1986) determinado por la obra de estos jóvenes escritores, posteriores al boom, que conformarían el Capítulo catalán. En cuanto a los integrantes y a las obras que hicieron parte de dicho Capítulo, podemos ver que Moreno-Durán no desconoce los diversos escritores que sin haber residido, publicaron en Barcelona por esa época — como es el caso de Gustavo Álvarez Gardeazábal, Manuel Mejía Vallejo, Pedro Gómez Valderrama, Manuel Zapata Olivella y Álvaro Mutis-; no obstante, de acuerdo con esa primera condición que se había identificado, solo reconocerá como parte de lo que sería el canon del Capítulo catalán las obras de aquellos que habrían vivido y publicado en Barcelona. Al respecto, Moreno-Durán (1986) dirá que

Las obras originalmente publicadas en dicho período son las siguientes: Dos veces Alicia y Misiá señora (Alba Lucía Ángel); Crónica de tiempo muerto y Jóvenes pobres amantes (Óscar Collazos); Hasta el sol de los venados (Carlos Perozzo); Sin nada entre las manos y Entre ruinas (Héctor Sánchez); Las ciento veinte jornadas de Bouvard y Pecuchet (Ricardo Cano Gaviria); Los parientes de Ester (Luis Fayad); mi trilogía Femina Suite, compuesta por Juego de damas, El toque de Diana y Finale caprioccioso con Madonna, así como el ensayo De la barbarie a la imaginación, el volumen Metropolitanas y la novela Los felinos del Canciller (p. 117).

Ahora, lo que podría pasar inadvertido del canon que Moreno-Durán establece es el hecho de que a través de este se presenta, indirectamente, como el mayor representante de este periodo. Nótese que de los autores que menciona, él mismo es el que tiene la mayor cantidad de títulos. Mientras el resto cuenta con una o dos publicaciones, Moreno-Durán cuenta con seis, lo cual lo convierte, si no en el más representativo escritor del "Capítulo catalán”, por lo menos en el más prolífico. Asunto que, atendiendo a las apreciaciones que hace R.H con relación al hecho de ser publicado, vendría siendo lo mismo. Observemos cuando dice:

Es así mismo cierto que muchos otros escritores colombianos visitaron, residieron o pasaron largas temporadas en Barcelona, y es también evidente que algunos de ellos desarrollaron un trabajo literario, así fuera efímero, durante su estadía. Sin embargo, la única forma de valorar ese trabajo y, sobre todo, de vincularlo vivencialmente a la actividad cultural de la ciudad, es a través de la fusión de la experiencia objetiva del autor con el medio donde se publica, es decir, la identificación del copyright con la ciudad donde la obra ve la luz (p. 117).

$\mathrm{Si}$ bien no existe una correspondencia necesaria entre lo cualitativo y lo cuantitativo, en el fondo es lo que parece sugerir Moreno- 
Durán con el tema de las publicaciones. Esta idea la hará más evidente cuando después de dedicarle un fragmento considerable al asunto de las múltiples dificultades que un escritor debe superar para ser publicado en el extranjero, termina sugiriendo que el libro, como resultado final, es la muestra de haberlas superado y que "[...] este hecho implica ya un valor cualitativo difícil de ignorar" (p. 118). Dado que el hecho de las publicaciones es, indudablemente, un factor esencial en un periodo literario, podemos decir que el "Capítulo catalán” se inicia en 1972 con la publicación de Dos veces Alicia, de Alba Lucía Ángel, y se cierra en 1987 con la publicación de Los felinos del canciller, de Rafael Humberto Moreno-Durán.

En conclusión, en el “Capítulo catalán” Moreno-Durán bosqueja el armazón de un momento de la literatura que estaba pasando inadvertido, y elabora las estrategias textuales para que alguna vez pudiera ser comprendido y actualizado. El autor tuvo plena consciencia del lugar que ocupó dentro del momento que se había esmerado por relatar, y sabía que una posible continuación de su libro implicaría que lo tuvieran en cuenta. Sin embargo, prefiere confiar esta continuidad histórica a la futura crítica. Sabe también que después de eso no queda otra cosa que esperar. Escribe el "Capítulo catalán" con la esperanza de quien lanza una botella al mar, pero lo hace con la certeza de que su mensaje será encontrado y atendido. Esta convicción nos la dará a conocer al final de "Parábola sobre el retorno":

[...] puedo decir desde ahora que, aunque mi nombre no quepa en la cartografía astral de este país, iré por ahí con mi luminosa melena seguro de que dentro de 76 años volveré a estar aquí, aunque me temo que no pueda afirmar lo mismo de mis contemporáneos (Moreno-Durán, en Rodríguez, 2017. Anexo viII, p. 123).

Retomando el paralelo cervantino, esta fe que Moreno-Durán deposita en la crítica futura comparte el mismo espíritu que manifiesta Quijote en su primera salida y se podría expresar con la misma gallardía que el Caballero de los leones lo habría hecho. Además, a quien esté familiarizado con la figura de Rafael Humberto Moreno-Durán no le resultará descabellado imaginarlo blasonando: "Dichosa edad y siglo dichoso aquel adonde saldrán a luz las famosas hazañas mías, dignas de entallarse en bronces, esculpirse en mármoles y pintarse en tablas, para memoria en lo futuro" (Don Quijote I, II, p. 35). 


\section{Referencias bibliográficas}

Cobo Borda, J. G. (1989). La narrativa colombiana después de García Márquez: y Otros ensayos. Bogotá: Editorial Tercer Mundo.

Giraldo, L. M. (2002). Después de las grandes rabias y los hermosos errores. En: Cuentos caníbales: antología de nuevos narradores colombianos (pp. 9-20). Bogotá: Alfagura.

Menton, S. (1978). La novela colombiana: planetas y satélites. Colombia: Plaza y Janés.

Moreno-Durán, R. (1986). La augusta sílaba (fragmentos). Capítulo catalán. Boletín cultural y bibliográfico 23 (9), pp. 114-122. Recuperado de: https://publicaciones. banrepcultural.org/index.php/boletin_cultural/article/view/3107/3194 [22.01.2019].

Moreno-Durán, R.H. (1995). Como el halcón peregrino. Colombia: Santillana, S.A.

Moreno-Durán, R.H. (1998). Denominación de origen: momentos de la literatura colombiana. Bogotá: Ariel.

Rama, Á. (1982). La novela en América latina. Panoramas 1920-1980. Colombia: Printer Colombiana S.A.

Restrepo, G. (2014). Constancia de una amistad. Memoria y diálogo. Aleph 170, pp. 8-29.

Rodríguez, J. C. (2017). El “Capítulo catalán” y la obra autobiográfica de Rafael Humberto Moreno-Durán (Tesis de Maestría). Universidad de los Andes, Bogotá. 